\title{
México en Centroamérica: del activismo de los años ochenta a la nueva agenda del siglo XXI
}

\section{Mónica Toussaint Ribot ${ }^{1}$}

Recepción: 18 de noviembre de 2013 / Aprobación: 9 de diciembre de 2013

\section{Resumen}

El artículo busca dar cuenta de la manera en que México se ha relacionado con la región centroamericana, de finales de los años setenta a la fecha, y evaluar su papel como actor político regional. Propone una explicación acerca de las causas del interés de los distintos gobiernos mexicanos en la región y estudia diversas instancias mediadoras y de cooperación como son el Grupo Contadora, el Mecanismo de Tuxtla, el Plan Puebla Panamá, el Proyecto Mesoamérica y el Sistema de Integración Centroamericana (SICA). Asimismo, plantea algunas preguntas en torno al futuro de la relación de México con la región en el marco de los mecanismos regionales de cooperación y los tratados de libre comercio.

\section{Palabras clave}

Crisis, paz, cooperación internacional, libre comercio, migración, seguridad

\section{Abstract}

This article wants to analyze the way in which Mexico has built his relation with Central America, from the late 70's to the present, and assess its role as a political regional actor. It proposes an explanation about the interest of the different Mexican governments in Central America and studies the different mechanisms of mediation and international cooperation such as Grupo Contadora, Mecanismo de Tuxtla, Plan Puebla Panamá, Proyecto Mesoamérica and Sistema de Integración Centroamericana (SICA). Finally, it makes some questions about the future of the relations of Mexico with the region, in the context of the regional cooperation mechanisms and the free trade agreements.

\section{Keywords}

Crisis, peace, international cooperation, free trade, migration, security

1 Mexicana. Doctora en Estudios Latinoamericanos por la Universidad Nacional Autónoma de México México. Profesora Investigadora del Instituto de Investigaciones Dr. José María Luis Mora, México. Correo electrónico: mtoussaint@mora.edu.mx 


\section{Resumo}

Este artigo pretende analisar a maneira pela qual o México tem construído sua relação com a América Central, a partir do final dos anos 70 até o presente, e avaliar o seu papel como um ator político regional. Apresenta uma explicação sobre as causas do interesse dos diferentes governos mexicanos na região, e estuda as diversas instancias mediadoras e de cooperação como o Grupo Contadora, o Mecanismo de Tuxtla, o Plano Puebla-Panamá, o Projeto Mesoamérica e o Sistema de Integração Centro-americano (SICA). Ao mesmo tempo levanta algumas perguntas sobre o futuro das relações do México com a região no âmbito dos mecanismos regionais de cooperação e acordos de livre comércio.

\section{Palavras-chave}

Crise, paz, cooperação internacional, livre comércio, migração, segurança

\section{Introducción}

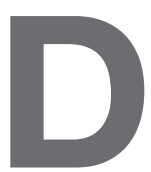

e fines de los años setenta a principios de los ochenta, la política de México hacia los países centroamericanos se puede caracterizar como una política activa que dio apoyo a los movimientos sociales en la región, se desarrolló de manera independiente con respecto a Estados Unidos y desempeñó un papel fundamental en la búsqueda de la paz en el área. El gobierno mexicano no solo debió hacer frente a una situación de guerra en el istmo centroamericano, que trajo consigo la presencia de decenas de miles de refugiados en su frontera sur, sino que tuvo que resistir las presiones de Washington y los embates de la opinión pública interna, que insistía en denunciar los costos de esta política.

En una segunda etapa, la diplomacia mexicana dio marcha atrás a su política activa hacia Centroamérica y, a partir de la creación del Grupo Contadora en 1983, se propuso emprender una acción conjunta con otros gobiernos latinoamericanos para alcanzar la paz en la región, aunque esta iniciativa a la postre no logró conseguir los objetivos planteados. En los años noventa, no obstante que México había volcado su interés hacia Estados Unidos con miras a la firma del Tratado de Libre Comercio con América del Norte (TLCAN), el gobierno mexicano tuvo una participación activa en las negociaciones para alcanzar la paz, primero en El Salvador, en 1992, y luego en Guatemala, en 1996.

Las relaciones entre México y Centroamérica experimentaron cambios importantes en el periodo de 1996 a 2006, algunos de ellos derivados de la transformación del escenario internacional y otros más surgidos a partir de la evolución política interna tanto de México como de los países del istmo. Los acuerdos de paz y los procesos de retorno de refugiados representaron la conclusión de la crisis política y abrieron la puerta a los nuevos temas en 
las agendas bilaterales y en el análisis de la problemática regional. Una vez alcanzada la paz en el istmo, el gobierno mexicano trasladó el eje de las relaciones con los países centroamericanos: de la participación política directa y la mediación para pacificar el área, se pasó a la construcción de mecanismos de cooperación para el desarrollo regional tales como las Cumbres de Tuxtla, el Plan Puebla Panamá y el Proyecto Mesoamérica.

En los últimos años, otros problemas fueron adquiriendo importancia creciente. Tal es el caso de la migración de centroamericanos indocumentados hacia Estados Unidos, pasando por territorio mexicano, así como el de las políticas de seguridad, tanto para enfrentar la delincuencia y la presencia de las maras, como para la contención de los flujos migratorios. A lo anterior se suma un tercer aspecto: la firma de los tratados de libre comercio entre México y los países del istmo en los años posteriores a la firma del TLCAN. De este modo, encontramos nuevas preocupaciones en la agenda regional, las cuales no pueden desligarse de la historia política reciente de los países del istmo, de la herencia de la crisis política y los años de guerra, así como del interés de México por consolidarse como un actor con un peso específico en la geopolítica del área.

\section{Centroamérica en crisis}

La crisis política que tuvo lugar en Centroamérica durante los años setenta del siglo XX tuvo sus raíces tanto en la historia interna de los países del istmo como en los factores externos. El modelo agroexportador subordinado a los intereses del capital estadounidense, se había caracterizado por el predominio y la concentración del poder en manos de los terratenientes, en detrimento de las masas rurales, lo que condujo a un elevado nivel de polarización social. Con el apoyo de Estados Unidos, las oligarquías en el poder se hicieron cada vez más autoritarias y represivas, incrementando el proceso de militarización y la consolidación de las dictaduras militares. Las consecuencias de este proceso se expresaron en una vida política excluyente, golpes de Estado, elecciones controladas, candidatos impuestos desde el gobierno, preeminencia del ejecutivo y muy poca posibilidad de expresión pública (Castillo, Toussaint y Vázquez, 2011, 127-128). Si bien las manifestaciones del deterioro social, económico y político fueron diferentes en Nicaragua, El Salvador y Guatemala, en todos los casos predominó una intensa lucha por dejar atrás la historia de regímenes carentes de prácticas democráticas. Las protestas sociales se incrementaron y, frente al fracaso de los partidos políticos tradicionales, las movilizaciones fueron encabezadas por organizaciones estudiantiles y el incipiente movimiento guerrillero, a lo cual se sumó la inconformidad de sectores cercanos a la oligarquía, como fue el caso de la Iglesia. A todo ello, la clase dominante respondió con una oleada creciente de represión, violencia y muerte (Cueva, 1987, 7-14; Torres Rivas, 1984, 23-51). 
El derrocamiento de la dictadura de Anastasio Somoza en Nicaragua en julio de 1979 y el inmediato ascenso del movimiento insurreccional en El Salvador y Guatemala, constituyen un punto de quiebre en la historia del istmo. A partir de entonces se inauguró una sangrienta etapa de guerra civil, en la que predominó el factor militar. El arribo del Frente Sandinista de Liberación Nacional (FSLN) al poder, gracias a su habilidad como grupo político, al desgaste del régimen somocista y al respaldo político internacional a la causa sandinista, suscitó un enorme entusiasmo entre las organizaciones de masas radicalizadas de El Salvador y Guatemala, acrecentando notoriamente la efervescencia insurreccional en la región (Castillo, Toussaint y Vázquez, 2011, 131-132). A principios de 1980, el movimiento revolucionario salvadoreño inició un proceso de unificación que culminó con la creación del Frente Farabundo Martí de Liberación Nacional (FMLN), al tiempo que los frentes populares se aliaron con partidos de izquierda para fundar el Frente Democrático Revolucionario (FDR). La insurrección inició con una movilización popular multitudinaria el 22 de enero de $1980^{2}$, a la cual se sumó una serie de sublevaciones en las áreas rurales del país, encabezadas por incipientes núcleos guerrilleros, que culminaron con la fallida "Ofensiva Final" del 10 de enero de 1981, convocada por el FMLN. Poco a poco las fuerzas revolucionarias se vieron gradualmente reducidas a las zonas rurales sublevadas mientras que, en las ciudades y en aquellas áreas del interior en las que la rebelión había sido derrotada, los sobrevivientes del movimiento popular fueron diezmados por los cuerpos represivos oficiales y los escuadrones de la muerte (Gordon, 1993, 23-25).

En Guatemala, el desarrollo del movimiento insurreccional se caracterizó por una extensa incorporación de las comunidades indígenas a la lucha insurgente. Sin embargo, la respuesta gubernamental al desafío revolucionario fue contundente y, en 1981, las estructuras políticas y militares de la guerrilla en la capital fueron desmanteladas casi por completo. Al año siguiente, la contrainsurgencia se volcó sobre el campo en una feroz campaña de "tierra arrasada", dirigida contra la población campesina sospechosa de respaldar a las organizaciones armadas. La gran mayoría de la población civil fue concentrada por el ejército en las llamadas "aldeas modelo" y obligada a enrolarse en las Patrullas de Autodefensa Civil. De aquellos que lograron huir, solo unos pocos permanecieron en territorio guatemalteco; cerca de la línea fronteriza formaron las llamadas Comunidades de Población en Resistencia (CPR) y, bajo la protección de la guerrilla, sobrevivieron en la selva hasta el fin del conflicto. Otros muchos buscaron protección en países vecinos, particularmente en México (Comisión para el Esclarecimiento Histórico, 1999; Castillo, Toussaint y Vázquez, 2011, 132-133).

Este fue el escenario centroamericano que generó una respuesta del gobierno mexicano a fines de la década de los setenta el cual, todavía bajo la

2 En marzo de ese mismo año fue brutalmente asesinado Monseñor Óscar Arnulfo Romero. 
influencia de la ideología nacionalista emanada de la revolución mexicana, desarrolló una política de Estado encaminada a apoyar a los movimientos sociales en la región. Dicha política tuvo también la finalidad de inyectar un nuevo elemento en la relación bilateral de México con Estados Unidos y consolidarlo como un actor político de primer orden en la región.

\section{Una política activa}

A raíz de la crisis política en el istmo centroamericano, el presidente José López Portillo apoyó a los movimientos de liberación nacional en Nicaragua y El Salvador por medio del otorgamiento de asilo en las sedes diplomáticas, la ruptura de relaciones con Anastasio Somoza en Nicaragua, el Comunicado franco-mexicano que daba a la guerrilla salvadoreña el carácter de fuerza representativa, y el reconocimiento al Gobierno Sandinista de Reconstrucción Nacional. Con esta política México deseaba contribuir a encontrar una salida democrática y pacífica a la crisis regional y, al mismo tiempo, lograr cierto margen de autonomía e independencia frente a Estados Unidos. Se trataba de una política de Estado que apoyaba a las fuerzas sociales que buscaban emprender transformaciones radicales en ambos países, la cual tenía como sustento el incremento en la capacidad negociadora de México a nivel internacional con base en el auge de los precios del petróleo (Toussaint, Rodríguez y Vázquez, 2001; Gordon, 1993, 15).

El objetivo estratégico del gobierno de López Portillo era garantizar la estabilidad política regional y eliminar un foco de tensión en su frontera sur. Centroamérica estaba demasiado cerca como para permanecer indiferentes, por lo que la política exterior no podía limitarse a la defensa de los principios, sino que debía asumir un carácter activo. El nivel de prioridad política otorgado a Centroamérica se modificó y la región se convirtió en un tema fundamental en la agenda internacional de México. A partir de entonces, empezaron a tratarse asuntos como el tipo de gobierno en Nicaragua, la situación políticomilitar en El Salvador, las relaciones de Estados Unidos con el gobierno sandinista y la posibilidad de un tratado de paz para los países del istmo (Castañeda y Pastor, 1989, 224-225).

México estaba dispuesto a aceptar, e incluso a respaldar, cambios políticos y sociales en Centroamérica. Se partía de la base de que los procesos revolucionarios que se estaban desarrollando no tenían su origen en una conspiración del comunismo internacional, como afirmaba el gobierno estadounidense, sino en los graves rezagos sociales y la intransigencia política de los regímenes autoritarios de la región. Por ello, y en contra de la opinión de Washington, México demandó el respeto a la autodeterminación de los pueblos y favoreció la negociación política como recurso para darle salida a la crisis regional, propugnando desde un principio por la inclusión de todas las partes en las negociaciones (Castillo, Toussaint y Vázquez, 2011, 137). Así, la intención 
de favorecer el cambio político en Centroamérica condujo al gobierno mexicano a brindarle respaldo diplomático y ayuda material al gobierno sandinista de Nicaragua, al tiempo que establecía vínculos con los grupos revolucionarios de El Salvador y Guatemala (Castañeda y Pastor, 1989, 225).

El 20 de mayo de 1979, México rompió relaciones con el gobierno de Anastasio Somoza debido a la violación masiva de los derechos humanos y a las acciones bélicas indiscriminadas de la Guardia Nacional en contra de la población civil de Nicaragua. Además, López Portillo realizó una campaña de proselitismo con el resto de los países latinoamericanos para que se sumaran al bloqueo diplomático contra Somoza y para que la Organización de los Estados Americanos (OEA) tomara cartas en el asunto. El objetivo de la medida era aislar políticamente a Nicaragua y lograr que Estados Unidos dejara de apoyar a Somoza (Castillo, Toussaint y Vázquez, 2011, 139-140). Un mes después, México encabezó en la OEA al grupo de países que bloqueó una iniciativa de Estados Unidos encaminada a constituir una fuerza interamericana de paz para restablecer el orden y asegurar las elecciones en Nicaragua (Garcés, 1982, 304). Asimismo, a partir del triunfo de la revolución sandinista, en julio del mismo año, México decidió colaborar con la Junta de Gobierno de Reconstrucción Nacional con la finalidad de conservar el carácter pluralista de la revolución. El 3 de agosto de 1980, en presencia del presidente de Costa Rica, Rodrigo Carazo Odio, los mandatarios de México y Venezuela, José López Portillo y Luis Herrera Campins, firmaron el Acuerdo de San José, por medio del cual se convirtieron en abastecedores de petróleo a los nicaragüenses con tasas preferenciales (Secretaría de Relaciones Exteriores, 1990, 82, 85; Castillo, Toussaint y Vázquez, 2011, 142-143; Ojeda, 2007, 133-134; Alcázar, 2013, 11).

Entre 1979 y 1982, México suscribió más de 200 acuerdos para desarrollar programas de asistencia técnica y económica con Centroamérica y el Caribe. En el caso de Nicaragua, además de fungir como aval de su deuda externa ante la banca internacional y suministrarle ayuda económica y técnica, se llevaron a cabo diversas inversiones conjuntas y se le otorgaron donativos y préstamos por más de 100 millones de dólares. Sin embargo, la escalada de la revolución en El Salvador a partir de 1980, el ascenso de Ronald Reagan al poder en enero de 1981, el incremento de las amenazas de intervención en Centroamérica, el aumento del flujo de refugiados salvadoreños y guatemaltecos, y la pérdida de apoyo por parte de Costa Rica y Venezuela, países que se tornaron críticos del régimen sandinista y otorgaron su respaldo al gobierno de José Napoleón Duarte en El Salvador, fueron factores que incrementaron las posibilidades de regionalización del conflicto y que, años después, contribuirían al repliegue de la política exterior mexicana en el área (Lafeber, 1985, 1-16; Castillo, Toussaint y Vázquez, 2011, 143).

Con el triunfo de Ronald Reagan en las elecciones presidenciales, Estados Unidos lanzó una campaña para controlar la situación política en el istmo cen- 
troamericano con base en una serie de acciones intervencionistas, justificadas con el argumento de la defensa de la seguridad nacional. Asimismo, a lo largo de su administración, Reagan luchó por hacer ver los conflictos en la región como producto de la confrontación Este-Oeste, lo que lo llevó a desarrollar la estrategia de Guerra de Baja Intensidad (Ojeda, 2007, 20). Esta buscaba dar marcha atrás (roll back) al proceso revolucionario nicaragüense por medio del apoyo financiero a las fuerzas de la Contra y, con el fin de que lo sucedido en Nicaragua no se repitiera, Reagan impulsó también una estrategia de contrainsurgencia en El Salvador y en Guatemala encaminada a combatir y derrotar a los movimientos revolucionarios en la región. Los recursos económicos invertidos por el gobierno de Washington fueron considerables y estuvieron destinados al apoyo económico para reforzar los ejércitos locales, al entrenamiento de los soldados guatemaltecos y salvadoreños, al financiamiento de la Contra nicaragüense y a la construcción de bases militares, aeropuertos y depósitos de armamento en Honduras. Con estas medidas se produjo un creciente proceso de militarización en la región que cada vez más parecía poner en riesgo la futura estabilidad política del área (Diskin, 1983, 43-62; Best, 1987, 32-66).

Durante 1981 y 1982, la diplomacia mexicana buscó fomentar la distensión entre las partes en conflicto. Las dos acciones más importantes impulsadas por el presidente López Portillo fueron la presentación del Comunicado franco-mexicano y la propuesta de un Plan Regional de Distensión. En agosto de 1981, México y Francia presentaron un Comunicado ante la ONU, elaborado en respuesta a la violación a los derechos humanos en El Salvador, en el cual se reconocía a las organizaciones revolucionarias salvadoreñas (Frente Farabundo Martí para la Liberación Nacional y Frente Democrático Revolucionario) con la calidad de fuerzas políticas representativas y con la legitimidad política para negociar con el gobierno ${ }^{3}$ (Benítez y Córdova, 1989b, 165). El objetivo de este comunicado consistía en encontrar una salida intermedia entre la guerrilla y la junta militar salvadoreña, por lo que se hacía un llamado a la comunidad internacional para propiciar la negociación entre las partes en conflicto, a fin de restablecer la paz y evitar cualquier tipo de intervención externa, en el marco de los principios de libre autodeterminación de los pueblos y no intervención. El comunicado constituyó un claro esfuerzo para detener la solución militar promovida por el gobierno de Reagan y tuvo una gran repercusión internacional, logrando atraer la mirada del mundo hacia lo que sucedía en El Salvador (Cuenca, 1984, 91; Páez, 1998, 166; Rico, 1991, 95; Ojeda, 2007, 23).

La otra acción de López Portillo al final de su mandato fue la propuesta de un Plan Regional de Distensión presentada en febrero de 1982, durante su visita a Managua en apoyo a la Junta de Reconstrucción Nacional. Esta iniciativa multilateral tenía como finalidad disminuir las tensiones y sentar las

3 La Declaración conjunta México-Francia fue leída y comentada a lo largo de la transmisión de Radio Venceremos del 29 de agosto de 1981. 
bases de negociación dirigidas a la realización de un esfuerzo sostenido hacia la paz, la estabilidad, la democracia y el desarrollo en Centroamérica (Benítez y Córdova, 1989b, 57). El plan proponía la búsqueda de una solución negociada para El Salvador, la formulación de un pacto de no agresión de Estados Unidos hacia Nicaragua y hacia el resto de los países centroamericanos, y el diálogo entre Cuba y Estados Unidos, para todo lo cual México se ofrecía como mediador. La iniciativa no prosperó, pero sentó un precedente importante acerca de la necesidad de un esfuerzo concertado para la paz en Centroamérica y constituyó uno de los antecedentes de la creación del Grupo Contadora un año después (Ojeda, 2007, 25-26).

En suma, la política activa de México hacia Centroamérica a fines de los años setenta y principios de los ochenta tuvo dos ejes fundamentales: uno, el apoyo a los movimientos sociales que luchaban en contra de los gobiernos autoritarios en la región, por distintas vías: asilo diplomático, ruptura de relaciones, iniciativas en los foros internacionales, programas de asistencia técnica y económica; otro, la búsqueda de la paz y la estabilidad regional en su frontera sur y la participación en las propuestas de distensión. En ambos sentidos, el gobierno del presidente López Portillo (1976-1982) desarrolló una serie de acciones las cuales tuvieron un costo que, a la postre, condujo a su sucesor, Miguel de la Madrid Hurtado (1982-1988) a replantear su política hacia el istmo centroamericano.

\section{La ruta de la negociación}

Durante los años ochenta, Centroamérica vivió una primera etapa caracterizada por un amplio despliegue militar, el escalamiento de los conflictos armados y la amenaza de la regionalización del conflicto, seguida de un segundo momento cuyo eje fue la búsqueda del establecimiento de mecanismos para alcanzar la paz. En un principio, el balance estuvo a favor de las fuerzas revolucionarias, por lo que Estados Unidos optó por mantener una presión constante hacia la región a lo largo de la década por medio del apoyo financiero a la política de contrainsurgencia (Castillo, Toussaint y Vázquez, 2011, 159).

Al llegar a la presidencia, Miguel De la Madrid encontró un país en crisis, la cual para muchos era el resultado de las sanciones impuestas a México por Estados Unidos debido a su política exterior hacia Centroamérica. Como la política exterior mexicana se había convertido en un problema para Washington, la CIA y algunos sectores del Departamento de Estado intentaron presionar a México para que la transformara y se alineara a Estados Unidos. El presidente de la Madrid inició entonces una intensa campaña diplomática en busca de aliados latinoamericanos para un nuevo esfuerzo de distensión en Centroamérica, teniendo como base la acción diplomática colectiva, lo que le permitiría a México mantener su influencia a nivel regional sin enfrentarse directamente a Estados Unidos (Ojeda, 2007, 36-40). En enero de 1983 tuvo lugar la reunión 
de los ministros de Relaciones Exteriores de Colombia, México, Panamá y Venezuela en la isla panameña de Contadora. El grupo, conocido desde entonces con el nombre de Contadora, se convirtió en la salida ideal para México a nivel internacional porque le permitía no alinearse frente a Estados Unidos y mantener una diplomacia relativamente activa. Sus objetivos eran detener una conflagración bélica en el área, crear condiciones de paz por medio de la eliminación de las armas y la presencia militar extranjera, e impulsar el desarrollo económico y social de la región (Sepúlveda, 1984, 407-414; Ojeda, 2007, 34). En particular, Contadora rechazó inscribir los conflictos en la confrontación este-oeste, como pretendía hacerlo el gobierno norteamericano, y optó por remarcar que su origen tenía que ver con la situación socioeconómica de cada uno de los países (Ojeda, 2007, 39; Herrera Lasso, 1990, 147).

Los primeros esfuerzos de Contadora se enfocaron a la definición de un programa general de respeto a los principios del derecho internacional: no intervención, autodeterminación, igualdad soberana delos Estados, cooperación para el desarrollo económico y social, y solución pacífica de las controversias (Valero, 1985, 203-204). Asimismo, se reconoció la importancia de fortalecer las instituciones políticas y democráticas de los países centroamericanos con el apoyo de la comunidad internacional (Ortiz, 1988, 37-38). Sin embargo, las propuestas de Contadora se vieron entorpecidas por la actitud belicosa de la administración Reagan contra el régimen sandinista en Nicaragua, así como por la desconfianza entre los Estados centroamericanos. A lo largo de 1984, Contadora se enfocó a la realización de una serie de reuniones de cancilleres para la elaboración de una propuesta de paz y cooperación, conocida como el "Acta para la paz y la cooperación en Centroamérica", la cual incluía temas como la desmilitarización del área, la democratización de la vida política y el fortalecimiento económico de los países de la región (Contadora, 1984, 85102; Arriola, 1986, 277). Nicaragua la aceptó, pero Honduras, El Salvador y Costa Rica formularon una serie de observaciones que bloquearon la iniciativa, por lo que el gobierno mexicano optó por promover el diálogo directo entre Washington y Managua (Rico, 1984, 78). Entre 1984 y 1985 se llevaron a cabo nueve rondas de negociaciones, que significaron un reconocimiento implícito de que Estados Unidos era parte del conflicto y, por lo mismo, su presencia era necesaria para avanzar en las negociaciones de paz. Sin embargo, ninguna de las partes estuvo dispuesta a ceder y no se alcanzaron resultados concretos (Ojeda, 2007, 119-125; Páez, 1998, 189-191).

Durante el tercer año de vida de Contadora, se inició un proceso de declive derivado del estancamiento de la negociación. Su margen de acción era cada vez más reducido debido a la rigidez de las partes en conflicto, al clima de confrontación e intolerancia en el área y a las reiteradas violaciones a las normas del derecho internacional por parte de Estados Unidos. En este contexto, en 1985 se dio un nuevo impulso en favor de una solución negociada 
en Centroamérica con la creación del Grupo de Lima o Grupo de Apoyo4, preocupado por encontrar soluciones a los problemas de la región (Castillo, Toussaint y Vázquez, 2011, 165-167). A pesar del deseo de diálogo, durante 1986 tuvo lugar la etapa final del Grupo Contadora. Las negociaciones de paz a lo largo del año no dieron ningún resultado: no se lograron acuerdos respecto a la fecha de la firma del Acta de Contadora, ni tampoco sobre los puntos referentes al control y reducción de armamentos y maniobras militares internacionales en la región. Por ello, Contadora comenzó a perder el apoyo en los foros internacionales. De ahí que el Grupo diera por terminados sus esfuerzos pacificadores y transfiriera la responsabilidad de encontrar los caminos para una paz negociada a los países centroamericanos (Ortiz, 1988, 386 y 389).

El nuevo escenario en Centroamérica, derivado de la llegada al poder en 1986 de Vinicio Cerezo en Guatemala y Óscar Arias en Costa Rica, facilitó la construcción de alternativas políticas que culminaron en mayo de ese mismo año con la realización de la I Cumbre presidencial centroamericana, en Esquipulas, Guatemala, la cual fue convocada para evaluar la situación centroamericana y el proceso de Contadora (Páez, 1998, 192; Benítez y Córdova, 1989a, 279-280). Al año siguiente, en agosto de 1987, tuvo lugar la reunión de Esquipulas II. En ella se establecieron los cimientos para el proceso de negociación de la paz en la región, retomando los principios de la iniciativa diplomática de Contadora, siendo respaldada por el prestigio democrático y pacifista de Costa Rica (Torres Rivas, 1984, 26). El clima de confianza mutua entre los gobiernos de la región generado en esta reunión hizo posible el inicio de una intensa actividad diplomática por medio de cumbres presidenciales, reuniones de vicepresidentes, juntas de cancilleres y conferencias de organismos regionales $^{5}$ (Rojas Aravena, 1990, 171-195). En ellas, los presidentes centroamericanos se comprometieron a buscar el diálogo para la concertación del cese al fuego y la amnistía general (Benítez y Córdova, 1989a, 438-440). Entre 1991 y 1995, se llevaron a cabo ocho Cumbres presidenciales centroamericanas más: dos en Costa Rica, dos en El Salvador, una en Honduras, una en Nicaragua, una en Panamá y una más en Guatemala. Los temas de la agenda fueron siempre la paz, la libertad, la democracia, el desarrollo y la búsqueda de la integración regional. Este proceso fue la base para la conformación del Sistema de Integración Centroamericana (SICA), creado en 1991 y que empezó a funcionar en 1993 (Castillo, Toussaint y Vázquez, 2011, 183-185).

De este modo, podemos afirmar que Contadora constituyó una iniciativa sin precedente encaminada a lograr la paz en la región. Sin embargo, el hecho de que no se llegara a firmar el Acta de Paz promovida por este grupo y que los países centroamericanos debieran asumir la conducción del proceso de

4 El Grupo de Apoyo estuvo formado por Argentina, Brasil, Perú y Uruguay.

5 Alajuela, Costa Rica, enero de 1988; Costa del Sol, El Salvador, febrero de 1989; Tela, Honduras, agosto de 1989; San Isidro de Coronado, Costa Rica, diciembre de 1989; Montelimar, Nicaragua, abril de 1990; y Antigua, Guatemala, junio de 1990. 
pacificación por la vía de las cumbres regionales, puede explicarse también por el papel que México desempeñó en este proceso. Al dar marcha atrás a la política activa y optar por construir un mecanismo de acción colectiva, para no enfrentarse de manera directa con Estados Unidos, el presidente Miguel de la Madrid logró frenar las presiones de Washington, pero debilitó en cierto modo la capacidad de negociación de Contadora.

\section{México y los acuerdos de paz}

El fin de la crisis centroamericana coincidió con la invasión de Estados Unidos a Panamá en 1989 y las elecciones nicaragüenses de 1990. Después de diez años de guerra, era evidente un cambio en el escenario internacional posterior a la caída del muro de Berlín, el cual afectaba directamente la correlación de fuerzas regional (Páez, 1998, 224 y 242). Después de que en noviembre de 1989 el FMLN lanzara una fuerte ofensiva militar, haciendo evidente la incapacidad del ejército de derrotar a las fuerzas revolucionarias, el gobierno salvadoreño decidió lanzar un ataque aéreo en las zonas urbanas controladas por la guerrilla y desatar una violenta represión contra los dirigentes opositores al régimen. Esta situación reforzó la necesidad de abrir el diálogo para alcanzar una paz negociada en El Salvador (Castillo, Toussaint y Vázquez, 2011, 188-189).

El proceso de paz inició en abril de 1990 con las negociaciones entre el gobierno salvadoreño y el FMLN, auspiciadas por Javier Pérez de Cuéllar, Secretario General de la ONU (Rouquié, 1994, 316). Con el ánimo de reunificar a la sociedad salvadoreña, en Ginebra se firmó un Acuerdo para resolver el conflicto armado por la vía de la negociación, el cual establecía objetivos, mecanismos y plazos, cuyo fin era alcanzar la pacificación e impulsar la democratización del país con estricto respeto a los derechos humanos (Benítez, 2001, 27). También se buscaba generar las condiciones necesarias para la reincorporación de los ex-combatientes del FMLN a la lucha política dentro de un marco de plena legalidad. A lo largo de ese año, hubo una reunión en Caracas y otra en Costa Rica para elaborar el calendario y la agenda de las negociaciones, al tiempo que se transitaba hacia los acuerdos sobre derechos humanos y el compromiso de cese al fuego. De especial relevancia fue la creación de una oficina de las Naciones Unidas como observadora de la situación en El Salvador, ONUSAL, así como la formación de un Grupo de Amigos del Secretario General de la ONU en apoyo a las negociaciones de paz, en el cual participaron los presidentes Carlos Salinas de Gortari de México, Carlos Andrés Pérez de Venezuela, César Gaviria de Colombia y Felipe González de España (Covarrubias y Muñoz, 2007, 189). En abril de 1991, se establecieron en México compromisos específicos en relación con la reforma constitucional enfocada a la transformación de las fuerzas armadas, a la modificación del sistema judicial y a los cambios en el sistema electoral. Asimismo, se propuso la creación de una Comisión de la Verdad encargada de investigar los hechos de violencia ocurridos en El Salvador desde principios de los años ochenta 
(Rouquié, 1994, 318). Las negociaciones continuaron en Nueva York durante septiembre, y en ellas se establecieron las condiciones para asegurar el cumplimiento de los acuerdos por parte de las partes involucradas (Castillo, Toussaint y Vázquez, 2011, 190).

El camino hacia la paz culminó el 31 de diciembre de 1991, cuando en la sede de las Naciones Unidas en Nueva York ambas partes se comprometieron a la firma de un acuerdo de paz definitivo ${ }^{6}$. Finalmente, el 16 de enero de 1992 tuvo lugar la firma de los Acuerdos de Paz entre el gobierno de El Salvador y la dirigencia insurgente en el Castillo de Chapultepec ${ }^{7}$, en los cuales se estableció una serie de puntos en los ámbitos judicial, electoral, económico y de seguridad (Covarrubias y Muñoz, 2007, 107-108, 189; Benítez, 2001, 28; Rouquié, 1994, 323). A lo largo del proceso, México realizó una importante contribución al proceso de paz en El Salvador, no solo como integrante del Grupo de Amigos del Secretario General de la ONU, sino por haber sido sede de 13 de las 23 rondas de negociación que facilitaron el diálogo entre las partes en conflicto. De la misma manera, desde enero de 1992, el gobierno mexicano envió un contingente policial en la Misión de las Naciones Unidas para El Salvador (ONUSAL) y el presidente Salinas de Gortari se comprometió a mantener la presencia de dicho contingente en ese país hasta la celebración de las elecciones presidenciales de marzo de 1994 (Benítez, 2001, 28). Posteriormente, a solicitud de la propia ONUSAL, cuatro oficiales mexicanos permanecieron un año más en El Salvador con el encargo de continuar con los trabajos de observación encabezados por las Naciones Unidas y participar en el proceso de seguimiento a los Acuerdos de Paz de El Salvador (Samayoa, 2007; Córdova, 2001, 105-133; Alcázar, 2013, 11).

El caso guatemalteco fue distinto al salvadoreño debido a que la guerrilla no estaba en posibilidad real de disputarle el poder al gobierno, pues se encontraba en una situación de debilidad y dispersión. Fue por ello que en las negociaciones para la paz pesaron más la presión internacional y la postura de los nuevos gobiernos centroamericanos de la segunda mitad de la década de los ochenta, preocupados por hacer un cambio para mejorar su imagen frente al mundo (Rouquié, 1994, 325). Son varias las etapas en el proceso de paz de Guatemala: diálogos informales iniciados en San José de Costa Rica en 1986; pláticas formales, primero en Madrid, España, en 1988, y luego en Oslo, Noruega, en 1990; otra ronda de negociaciones que se inició en México, en 1991; y una cuarta en 1994, que también comenzó en México, la cual culminó con la firma de los Acuerdos de Paz entre el gobierno y la guerrilla a fines de 1996 (Reyes, 1997, 47).

6 Jorge Montaño, representante de México en la Organización de las Naciones Unidas, participó en estas negociaciones entre el FMLN y el gobierno salvadoreño.

7 Los acuerdos se firmaron en México como un reconocimiento al papel desempeñado por el gobierno mexicano en la negociación. 
Al igual que en el caso salvadoreño, el Secretario General de la ONU propuso la creación de un Grupo de Amigos, el cual se conformó en 1993 por Colombia, España, Venezuela, Estados Unidos, Noruega y México, que asumió la coordinación. Finalmente, el 29 de diciembre de ese mismo año se firmó el Acuerdo de Paz entre el gobierno de Guatemala y la Unidad Revolucionaria Nacional Guatemalteca (URNG) y, dado que el gobierno de México tuvo una participación destacada en las negociaciones, el presidente Ernesto Zedillo fue invitado como testigo de honor en la ceremonia que tuvo lugar en la ciudad de Guatemala (Covarrubias y Muñoz, 2007, 158).

Puede resultar paradójico que, a pesar del gran interés del presidente Carlos Salinas de Gortari por negociar el Tratado de Libre Comercio con América del Norte (TLCAN), este se mostrara dispuesto a voltear los ojos hacia el sur y participara de manera activa en el proceso para alcanzar la paz en El Salvador. Lo mismo puede pensarse del presidente Ernesto Zedillo y su interés por ser parte de los acuerdos de paz de Guatemala. Sin embargo, es claro que ambos buscaron capitalizar los logros políticos internacionales de los gobiernos anteriores, al tiempo que trataban de fortalecer por todos los medios la posición de México dentro del panorama geopolítico regional.

\section{Del activismo a la cooperación}

La política activa de México hacia Centroamérica fue dando marcha atrás, primero durante el sexenio de Miguel de la Madrid, y luego durante los dos últimos gobiernos del Partido Revolucionario Institucional (PRI) del siglo XX: el de Carlos Salinas de Gortari y el de Ernesto Zedillo. Poco a poco, el activismo en la política exterior mexicana hacia la región fue sustituido por una política de cooperación para el desarrollo (Álvarez, 2001, 153-170; Lozoya, 2001, 935). A partir de entonces, se inició un proceso de institucionalización de la cooperación mexicana con Centroamérica, que culminó con la firma de los tratados de libre comercio con los países de la región (Rocha, 2006, 332-333).

Durante el primer año de su gobierno, Carlos Salinas de Gortari hizo explícita la necesidad de estrechar la cooperación con Estados Unidos, pero también afirmó la conveniencia de un mayor acercamiento con América Latina. Por ello, el gobierno continuó con el diálogo político hacia Latinoamérica y desarrolló una labor de concertación en los procesos de pacificación de El Salvador, Guatemala y Colombia (Castillo, Toussaint y Vázquez, 2011, 207). Así, al inicio de la década de los noventa, México impulsó una serie de iniciativas multilaterales de cooperación. En noviembre de 1990 se creó la Comisión Mexicana para la Cooperación con Centroamérica (CMCCA), concebida como un mecanismo para la coordinación de proyectos y acciones de cooperación con Centroamérica, impulsadas por las entidades del sector público, y en enero de 1991 se realizó en Tuxtla Gutiérrez, Chiapas, la Cumbre de presidentes de México y Centroamérica, conocida como Tuxtla I (Sosnowska, 2006, 68-69; 
Alcázar, 2013, 11). En esta Cumbre se reunieron el presidente de México, Carlos Salinas de Gortari, y sus homólogos de Guatemala, El Salvador, Honduras, Nicaragua y Costa Rica. El objetivo de la reunión consistió en suscribir varios acuerdos para fortalecer los procesos de pacificación y democratización en la región por medio de la cooperación internacional (Declaración Conjunta, 1991). Asimismo, en 1992 México se incorporó como socio extra-regional del Banco Centroamericano de Integración Económica y, entre 1991 y 1995, se llevaron a cabo 4,535 acciones de cooperación en los rubros económico, financiero y comercial, educativo-cultural y científico (Rocha, 2006, 333; Castillo, Toussaint y Vázquez, 2011, 210).

Los objetivos prioritarios de los gobiernos de los países centroamericanos eran la pacificación, la democratización y la desmilitarización de la región, al tiempo que intentaban rescatar los procesos de integración iniciados en la década de los sesenta. De aquí la suscripción del Protocolo de Tegucigalpa, en diciembre de 1991, mediante el cual se constituyó el marco jurídico e institucional para la creación del Sistema de Integración Centroamericana (SICA), organización regional encaminada a favorecer la paz, la democracia y el desarrollo sustentable en la región ${ }^{8}$ (Santamaría, 2008, 161-173). Además, en 1994, durante el último año del gobierno del presidente Salinas, se suscribió el Acuerdo General de Cooperación con el fin de establecer las bases para la firma de un Acuerdo de Complementación Económica entre México y Centroamérica (Alcázar, 2013, 12).

Durante el primer año de su administración, el presidente Ernesto Zedillo visitó los siete países centroamericanos para reafirmar el interés del gobierno mexicano en la cooperación bilateral y darle un mayor impulso a la cooperación regional. En 1996 tuvo lugar la Segunda Reunión de Jefes de Estado y de Gobierno de Centroamérica en San José, Costa Rica, en la cual participaron también los presidentes de Belice y Panamá. En esta reunión, conocida como Tuxtla II, se institucionalizó el Mecanismo de Diálogo y Concertación para analizar periódicamente los asuntos regionales, hemisféricos y mundiales, concertar posiciones conjuntas en los foros multilaterales, impulsar proyectos económicos conjuntos, apoyar el desarrollo sustentable y acordar acciones de cooperación (Declaración Conjunta, 1996; Alcázar, 2013, 12). Dos años más tarde, en julio de 1998, tuvo lugar en San Salvador la Tercera Reunión de Jefes de Estado y de Gobierno de Centroamérica (Tuxtla III). En ella se acordó continuar impulsando el diálogo político, promover el desarrollo económico-comercial, establecer una agenda de trabajo en áreas prioritarias, así como llevar a cabo un Programa de Cooperación Regional 1998-2000 (Declaración Conjunta, 1998). De manera simultánea, en ese mismo año, la Secretaría de Relaciones Exteriores creó el Instituto Mexicano de Cooperación Internacional

8 Sus miembros fundadores son Guatemala, El Salvador, Honduras, Nicaragua, Costa Rica y Panamá. Posteriormente, Belice se adhirió como Estado miembro y República Dominicana como Estado asociado. Asimismo, en la categoría de Estados observadores participan México, España y Taiwán. 
(IMEXCl) con la finalidad de agrupar las actividades de cooperación con Centroamérica y el Caribe y, de esta forma, fortalecer la integración y el desarrollo sustentable en la región (Lozoya, 2001, 931; Rocha, 2006, 333).

Con estos antecedentes, en la Cuarta Reunión de Jefes de Estado y de Gobierno en Centroamérica (Tuxtla IV), realizada en la ciudad de Guatemala en el año 2000, se planteó la redefinición de Mesoamérica con base en la idea de que México y Centroamérica son un área con problemas e intereses comunes y se definió como objetivo revisar, renovar o ampliar los acuerdos anteriores (Declaración Conjunta, 2000). A partir de entonces, se dejó de hablar de mexicanos y centroamericanos y, en su lugar, se empezó a hablar de mesoamericanos, al tiempo que se insistió en la necesidad de atender las áreas prioritarias y se enfatizó la importancia de incluir iniciativas para reducir la vulnerabilidad social y favorecer el desarrollo sustentable en la región mesoamericana.

Las iniciativas mexicanas de cooperación han tenido altas y bajas. La estructura institucional de la Secretaría de Relaciones Exteriores ha contribuido a fortalecer este tipo de programas y, en mucho, ha contribuido a dar continuidad a los proyectos. No obstante, las cifras no son halagadoras y, en términos generales, sólo un $25 \%$ de los convenios firmados son llevados a la práctica. Muchos de ellos se quedan solo en el papel y no van más allá de las buenas intenciones y, otros más, se enfrentan a severos problemas de falta de recursos e incapacidad de los gobiernos para cumplir con lo acordado. Por ello, resulta ilusorio pensar que el eje fundamental de la política exterior de México hacia Centroamérica pueda ser la cooperación, dejando de lado un compromiso certero con las reivindicaciones sociales en la región.

\section{Los proyectos regionales}

A finales de 2001, el presidente electo de México, Vicente Fox, se reunió con los presidentes de Centroamérica para promover un plan de desarrollo e integración regional desde Puebla hasta Panamá, cuyo objetivo era combatir el rezago social y económico por medio de la inversión en infraestructura ${ }^{9}$ (Serna, 1998, 220-221). En junio del año siguiente, tuvo lugar en San Salvador una Cumbre Extraordinaria de mandatarios de los países integrantes del Mecanismo de Tuxtla (Tuxtla V), con el propósito de lanzar oficialmente el Plan Puebla Panamá para la región sur-sureste de México y los países del istmo centroamericano (Declaración Conjunta, 2001; Alcázar, 2013, 12-13). Las tres dimensiones del Plan Puebla Panamá (PPP) eran el crecimiento económico, el manejo sustentable de los recursos naturales y el desarrollo social y humano. A partir de estos tres ejes se establecieron ocho iniciativas mesoamericanas, cada una de las cuales fue asignada a uno de los países para su promoción,

9 El Plan Puebla Panamá fue propuesto por Vicente Fox a los presidentes centroamericanos y al primer ministro de Belice el 30 de noviembre de 2000, un día antes de asumir el cargo como presidente constitucional de México. 
seguimiento y cumplimiento de objetivos: desarrollo sustentable (Nicaragua), desarrollo humano (México), prevención y atención a desastres (Panamá), turismo (Belice), intercambio comercial (Honduras), integración vial y transporte (Costa Rica), interconexión energética (Guatemala), servicios de telecomunicaciones (El Salvador) (Serna, 1998, 221-222). Durante la VI Cumbre del Mecanismo de Tuxtla que tuvo lugar en Managua, Nicaragua, en marzo de 2004, los Jefes de Estado y de Gobierno suscribieron el Acta que institucionalizó el Mecanismo del Plan Puebla Panamá, en la cual quedaron establecidas sus instancias principales: Cumbre de presidentes y Comisión Ejecutiva. En la reunión de Tuxtla VI se aprobaron además las cumbres anuales y el ingreso de México al Sistema de Integración Centroamericana (SICA), el cual se formalizó en noviembre de ese mismo año (Declaración Conjunta, 2004).

Deseoso de resaltar el interés de México en la región, entre 2004 y 2006 Vicente Fox realizó una serie de visitas a El Salvador, Panamá, Guatemala, Honduras y Nicaragua con la finalidad de promover acciones coordinadas para fortalecer el intercambio de información e intensificar los programas de cooperación en materia de infraestructura, libre comercio, energía, seguridad y combate al narcotráfico (Sosnowska, 2006, 79-80). Igualmente, México recibió a los presidentes de Guatemala, Honduras y El Salvador. En este periodo los temas fundamentales de la agenda entre México-Guatemala fueron el comercio bilateral, la infraestructura, la salud fronteriza, la cooperación técnica y el turismo. Sin embargo, algunos de los proyectos de cooperación solo quedaron en el papel e incluso algunos fueron cancelados (Castillo, Toussaint y Vázquez, 2011, 217-218).

Al inicio de la administración de Felipe Calderón, se buscó dar nuevo impulso a la relación con la región centroamericana para lo cual, en abril de 2007, se celebró en la ciudad de Campeche la Cumbre Extraordinaria para el fortalecimiento del Plan Puebla Panamá. Su objetivo era consolidar el proyecto de integración centroamericana, para lo cual se debían revisar los avances alcanzados por el mecanismo regional, asumir una serie de compromisos orientados a reposicionarlo, consolidarlo como un instrumento eficaz para promover el desarrollo y la prosperidad regional, y favorecer su articulación con el SICA (Declaración Conjunta, 2007; Proyecto Mesoamérica). Sin embargo, no hubo un tránsito del nivel discursivo a las acciones concretas, las iniciativas generales no dieron paso a proyectos con un impacto efectivo en las condiciones de vida de la población y no hubo una real voluntad política para dedicar los recursos humanos y económicos necesarios para que el PPP funcionara (Castillo, Toussaint y Vázquez, 2011, 219; Velázquez y Domínguez, 2013, 495; González y Velázquez, 2013, 609)

El evidente fracaso del PPP y las constantes críticas de la sociedad civil orillaron al gobierno de México a emprender un proceso de "reestructuración y fortalecimiento" del plan a partir de la X Cumbre del Mecanismo de Diálogo y Concertación de Tuxtla, realizada en Villahermosa, Tabasco, en junio de 2008 
(Declaración Conjunta, 2008). De aquí que el PPP se transformara en el Proyecto de Integración y Desarrollo de Mesoamérica, cuya finalidad fue definida como la gestión y ejecución de proyectos orientados a mejorar la calidad de vida de los habitantes de Mesoamérica a través de cuatro ejes: fortalecer la institucionalidad, mejorar la articulación con otros mecanismos regionales, establecer procesos sistemáticos de gestión de proyectos, y mejorar la comunicación de objetivos y logros (Proyecto Mesoamérica; Alcázar, 2013, 13). Una vez definidas las prioridades, se establecieron siete proyectos emblemáticos: interconexión eléctrica, telecomunicaciones, transporte, comercio, salud pública, sustentabilidad ambiental, reducción de desastres (Declaración Conjunta, 2008).

Sin embargo, las dificultades para llevar a cabo los objetivos del Proyecto Mesoamérica han sido evidentes. La primera está relacionada con la capacidad de gestión de los distintos gobiernos para obtener recursos, la disposición de los organismos financieros internacionales para el otorgamiento de estos, y las posibilidades presupuestales internas de cada uno de los países. La segunda apunta a que, más allá de los cambios en la estructura organizacional y en la dinámica de trabajo, persiste una buena cantidad de instancias organizativas, técnicas y de enlace que hacen más compleja la estructura y dificultan la operatividad de los proyectos. Y, la tercera, que está vinculada a la idea de que el Proyecto Mesoamérica se interesa más en garantizar las condiciones para el libre tránsito de mercancías y contribuir al fortalecimiento de los tratados de libre comercio, que en buscar el desarrollo y la prosperidad de los habitantes de la región.

Ha sido clara la ineficacia de estos proyectos regionales que, al menos en el papel, buscaban combatir los rezagos económicos y promover el desarrollo en el sur de México y en los países del istmo centroamericano. Las causas de este fracaso son muchas: falta de recursos, incapacidad de desarrollar los proyectos de cara a las comunidades, exceso de instancias de planeación y pocos resultados concretos, ausencia de mecanismos para dar seguimiento a los objetivos planteados. Lo que resulta lamentable es la cantidad de recursos invertidos en dar difusión a estos proyectos, sin que hubiera un correlato material de los mismos que operara realmente en beneficio de los pobladores de esta área.

\section{Migración y seguridad}

Como se dijo antes, la ausencia de canales democráticos en Guatemala, El Salvador y Nicaragua y los enfrentamientos armados entre las organizaciones guerrilleras y los ejércitos nacionales a fines de los años setenta y principios de los ochenta, motivaron el desplazamiento de decenas de miles de centroamericanos dentro de su propio país, así como hacia México, Estados Unidos y Canadá (Castillo, 2005, 67; Castillo y Herrera, 2006, 3). De manera particular, el conflicto armado en Guatemala alcanzó niveles muy profundos de violencia 
y represión en contra de los insurgentes y de las poblaciones que supuesta o realmente los apoyaban. De aquí que en Chiapas se asentaran decenas de miles de refugiados guatemaltecos en más de 100 campamentos dispersos a lo largo de la frontera de México con Guatemala ${ }^{10}$ (Comisión Mexicana de Ayuda a Refugiados, 2000, 12; Castillo y Toussaint, 2010a, 90). Desde la llegada de los refugiados guatemaltecos a Chiapas surgieron muchas voces en la propia administración gubernamental, principalmente en la Secretaría de Gobernación, que veían este fenómeno como un riesgo y una amenaza para la seguridad nacional. Por ello, el gobierno de México resolvió reubicar a esta población en los estados de Campeche y Quintana Roo, con el propósito de evitar los conflictos en el área fronteriza al tiempo que se continuaba garantizando protección y asistencia a los refugiados ${ }^{11}$ (Comisión Mexicana de Ayuda a Refugiados, 2000, 14).

Durante los últimos años del siglo XX, las economías y las sociedades centroamericanas entraron en crisis, principalmente en el sector de subsistencia agrícola, y se profundizó el fenómeno de la migración desde el campo, tanto hacia las ciudades como hacia el exterior (Castillo, 2000, 135). Hasta ese momento, la región fronteriza había sido escenario de la movilidad de población básicamente guatemalteca pero, a partir de entonces, hubo un aumento considerable en el flujo de salvadoreños, hondureños y nicaragüenses, el cual se mantuvo en crecimiento, incluso después de los acuerdos de paz en El Salvador y Guatemala en la década de los noventa (Rodríguez, 2006, 2; Castillo y Toussaint, 2010a, 90). Para el gobierno mexicano, la migración se convirtió en un tema de seguridad y de presión por parte del gobierno de Estados Unidos. Además, la población migrante pronto se volvió presa fácil de una serie de actores que buscaban aprovecharse de su necesidad de apoyos para lograr su objetivo (Ruiz, 2001, 7-33).

Ante la tendencia creciente del flujo migratorio, en México comenzaron a adoptarse medidas para contenerlo como el llamado Plan Sur, que se llevó a cabo al principio de la administración del Presidente Fox. Se trataba de coordinar a las autoridades de los diversos órdenes (federal, estatal y municipal), con base en la creación de un esquema de operativos y acciones coordinados desde la frontera México-Guatemala, en el estado de Chiapas, hasta el istmo de Tehuantepec, para establecer cinturones consecutivos de vigilancia que permitieran interceptar a los migrantes indocumentados en la ruta hacia el norte del país. Sin embargo, el Plan Sur resultó inoperante y poco efectivo, por la complejidad en la tarea de controlar el tránsito de personas en un territorio tan amplio, por la persistencia de mecanismos de corrupción entre los conductores y las autoridades, por la escasez de recursos materiales, técnicos y humanos

10 De los más de 100,000 refugiados que ingresaron a México a principios de los años ochenta, oficialmente solo se reconocieron a 46,000.

11 A mediados de la década, se reubicó aproximadamente a poco más de 18 mil refugiados y los demás permanecieron en Chiapas. 
necesarios para su aplicación, y por la falta de confianza en que por este medio se podrían contener los flujos migratorios indocumentados. Más adelante, la persistencia del flujo hizo que el gobierno mexicano insistiera con sus contrapartes centroamericanas para establecer mecanismos de cooperación con el propósito de hacer más eficientes los aseguramientos y las deportaciones de ciudadanos de los países de la región vecina. Por ello, se suscribieron una serie de acuerdos para "la repatriación digna y segura" de ciudadanos de Guatemala, El Salvador, Honduras y Nicaragua, a imagen y semejanza de los suscritos por México con el gobierno de Estados Unidos para la repatriación de sus connacionales. Sin embargo, hasta ahora el balance ha sido poco favorable para los migrantes (Castillo, Toussaint y Vázquez, 2011, 245-247).

El tema de la seguridad en las fronteras ha estado siempre presente en el ámbito de las relaciones de México con sus vecinos centroamericanos. Sin embargo, desde septiembre de 2001 este tema se vinculó de manera creciente con los procesos de gestión y administración de las migraciones en la frontera sur de México, especialmente por las presiones del gobierno de Estados Unidos que empezó a considerar al territorio mexicano como parte de su perímetro de seguridad (Castillo y Toussaint, 2010b, 270 y 290). A ello se sumaron las presiones de los organismos internacionales, que han exigido incrementar los controles fronterizos en virtud de que al fenómeno del tráfico se ha sumado el de la trata de personas (Alba y Kruijt, 2007, 492; Castillo, Toussaint y Vázquez, 2011, 249). En este sentido, destaca el establecimiento en 2003 de cuatro nuevos cruces fronterizos, como una manera de ordenar los flujos migratorios, turísticos y comerciales en el límite sur de México, así como de promover el desarrollo de las comunidades fronterizas. Con la presencia permanente de autoridades migratorias en los cruces se buscó combatir el tráfico ilegal de personas y mercancías que se había convertido en un problema de seguridad. Paralelamente, se intensificaron los trabajos de la Comisión Internacional de Límites y Aguas (CILA), dirigidos a la conservación de la brecha fronteriza, la construcción de monumentos limítrofes intermedios, el mantenimiento de monumentos ya existentes y la realización de levantamientos topográficos (Castillo, Toussaint y Vázquez, 2011, 218).

Para complicar más la situación, desde mediados de los años noventa se empezó a observar la presencia de bandas de maras en la frontera de Chiapas y Guatemala, concentrando su espacio de acción alrededor de las vías del tren en el tramo de Ciudad Hidalgo a Tapachula. Su principal objetivo era asaltar a los migrantes que transitaban por esa zona, los cuales se convirtieron en un grupo vulnerable e indefenso frente a la acción de estas pandillas (Ángeles, 2004, 95; Castillo y Toussaint, 2010a, 94). Es por ello que las relaciones erróneas entre migración y hechos criminales han permeado una visión del fenómeno que promueve la adopción de esquemas y medidas desde la seguridad nacional, en tanto la equiparan a otros fenómenos que se califican como amenazas. De ahí que, en 2002, México, Guatemala y Belice crearan 
un mecanismo denominado Grupo de Alto Nivel sobre Seguridad Fronteriza (GANSEF), cuyo propósito consistía en enfrentar al terrorismo y al crimen organizado, así como combatir los delitos vinculados con la migración y el tráfico ilícito de mercancías. Este se reunió por primera vez en marzo de 2003 y estableció como temas de discusión los asuntos fronterizos relacionados con la migración, los derechos humanos, el terrorismo internacional, el crimen organizado, la cooperación jurídica, la seguridad pública y las aduanas (Castillo y Toussaint, 2010a, 94).

Aunque con el cambio de gobierno en 2006 se perdió parte de este impulso, han tenido lugar varias reuniones del GANSEF con el objetivo de examinar los avances en los mecanismos de cooperación para la seguridad entre los tres países. No obstante, ante el incremento de la inseguridad en México y la penetración de bandas de narcotraficantes a través de las fronteras terrestres y marítimas, las autoridades mexicanas han insistido en la necesidad de reforzar la vigilancia en la frontera sur, para lo cual se consideró necesario el fortalecimiento de este mecanismo de coordinación y elaboración de políticas conjuntas. Es por ello que, para enfrentar a los grupos criminales, terroristas y al narcotráfico con un solo plan de acción, se propuso que los programas de seguridad abarquen otros problemas como el tráfico de personas y de vehículos, al tiempo que se pretende lograr una migración ordenada y segura como parte de un esfuerzo compartido de los tres gobiernos (Rico, 2008, 8; Castillo, Toussaint y Vázquez, 2011, 256-257; Alcázar, 2013, 20).

Un elemento relevante en el tema de la seguridad es la llamada Iniciativa Mérida, sin duda un proyecto importante del gobierno de Felipe Calderón, la cual tuvo su origen en la visita del presidente George W. Bush a Guatemala y a México en marzo de 2007. En virtud de que el problema de seguridad pública había alcanzado dimensiones críticas en ambos países y se estaba convirtiendo en un asunto regional, se vio la necesidad de formular estrategias conjuntas con base en la cooperación, la reciprocidad y la responsabilidad compartida (Rico, 2008, 11-12; Benítez, 2007, 13-15; Castillo y Toussaint, 2010a, 94). La Iniciativa Mérida se presentó como un paradigma de cooperación internacional en materia de seguridad y como el inicio de una nueva etapa en la cooperación bilateral México-Estados Unidos. Sin embargo, para muchos analistas constituyó un modelo de cooperación fracasado que trajo consigo mayor corrupción y un nivel de violencia incontrolable (Covarrubias, 2013, 462-467). Además, esta iniciativa también implica que el gobierno mexicano se subordine a los dictados de Washington en un esfuerzo por reforzar la vigilancia y sellar la frontera sur para evitar que los migrantes centroamericanos lleguen a Estados Unidos, obstaculizando los flujos migratorios que son legítimos y cada vez más importantes para la salud económica del país. Para evitar este problema, México debe definir si considera a los migrantes centroamericanos como elementos de impulso a la economía, al menos en ciertas regiones, o como un flujo no deseado (Castillo, Toussaint y Vázquez, 2011, 255-256). 
Hoy vemos con preocupación cómo al tema del creciente flujo migratorio, derivado de las precarias condiciones de vida de la mayoría de los habitantes de los países centroamericanos, se ha sumado el problema de la seguridad. Este tiene diversas aristas y pasa por al menos tres aspectos: la inseguridad y la violencia creciente en los lugares de origen, la vulnerabilidad de los espacios fronterizos, y las amenazas para los migrantes a lo largo del trayecto hacia el norte en busca de mejores oportunidades. Desafortunadamente, las medidas para combatir estos problemas han resultado insuficientes y han estado condicionadas más por la preocupación del gobierno de Estados Unidos, deseoso de cerrar su frontera, que por la búsqueda de programas de protección para los migrantes en tránsito.

\section{De la cultura al libre comercio}

Durante la segunda mitad del siglo XX, la cooperación entre México y las repúblicas centroamericanas se enfocó sobre todo al campo educativo y cultural. El primer convenio de esta índole se firmó con Guatemala en la década de los sesenta, después de la visita del presidente Gustavo Díaz Ordaz a la región, con el fin de fomentar el conocimiento de las respectivas culturas, costumbres y actividades en el campo de las humanidades, las artes, las ciencias y la tecnología. Diez años después, se firmó con Guatemala un nuevo convenio relativo a la protección y restitución de monumentos arqueológicos, artísticos e históricos. Ya en los años ochenta y gracias al interés en Centroamérica derivado de la actividad en la política exterior hacia el istmo centroamericano, se firmaron tres convenios más de cooperación: uno de intercambio cultural con Belice y dos de cooperación turística, con Costa Rica y con Guatemala. En estos años también se llevó a cabo la firma de un Acuerdo de Cooperación Económica, científico-técnica, cultural y educativa entre México y Nicaragua, el cual constituyó una clara forma de apoyo del gobierno mexicano hacia los sandinistas en el poder (Castillo, Toussaint y Vázquez, 2011, 225-226).

Una vez creada la Comisión Mexicana de Cooperación con Centroamérica en los años noventa, los acuerdos emanados de las reuniones de Tuxtla llevaron a la firma de una gran cantidad de convenios y acuerdos con los países centroamericanos: seis de cooperación técnica y científica, con Belice, El Salvador, Honduras, Nicaragua, Belice y Guatemala; cuatro de cooperación educativa y cultural, con Costa Rica, El Salvador, Honduras y Nicaragua; tres relativos a la protección y restitución de monumentos arqueológicos, artísticos e históricos, de los cuales uno fue firmado con El Salvador y dos con Belice; y cuatro más en materia de cooperación turística, suscritos con Belice, Nicaragua, Honduras y El Salvador. En este marco, destacan tres temas de interés en materia de tratados bilaterales para los gobiernos de México y Centroamérica, durante más de dos décadas. Uno de ellos era el relativo al entorno fronterizo de México con Guatemala y Belice, y abarcaba aspectos como límites y aguas, conservación de recursos naturales, protección y mejoramiento del ambiente, 
cooperación para la prevención y atención en casos de desastres producidos por fenómenos naturales y cuestiones sanitarias; otro hacía referencia al narcotráfico; y el último estaba relacionado con la extradición y la asistencia jurídica mutua en materia penal, en función de la lucha contra la delincuencia y el crimen organizado² (Castillo, Toussaint y Vázquez, 2011, 227-229).

De manera especial se debe hacer referencia a los tratados de libre comercio entre México y los países centroamericanos. Con el objetivo de crear una zona de libre comercio e impulsar el proceso de integración regional entre México y Centroamérica, en los años noventa el gobierno mexicano impulsó la firma de tres tratados de libre comercio: uno con el llamado Triángulo del Norte (Guatemala, El Salvador y Honduras), otro con Nicaragua y uno más con Costa Rica. La firma de los tratados de libre comercio buscaba estimular la expansión y diversificación del comercio de bienes y servicios, facilitar la circulación de mercancías, eliminar las barreras al comercio, promover condiciones de competencia leal en el comercio, suprimir aranceles, adoptar medidas sanitarias y fitosanitarias, proteger y hacer valer los derechos de propiedad intelectual, incrementar las oportunidades de inversión, así como proteger y dar seguridad jurídica a los inversionistas (Castillo, Toussaint y Vázquez, 2011, 230). Sin embargo, las negociaciones no fueron fáciles. Algunos productores centroamericanos expresaron su temor a la liberalización comercial con México por la posibilidad de una llegada masiva de productos mexicanos a la región, por las dificultades para ingresar al mercado mexicano o porque México no aceptara la entrada de productos manufacturados. Por su parte, los empresarios mexicanos, presentes en la región desde hacía varias décadas, estaban interesados en el acercamiento pues pensaban que este les abriría oportunidades en sectores tales como telecomunicaciones, turismo, construcción y servicios. Entre las empresas de capital mexicano interesadas en invertir en los países del istmo destacaban Telmex, Maseca, Celanese, Transportación Marítima Mexicana, Cementos Apasco, Elektra, Televisión Azteca e Ingenieros Civiles Asociados (Macouzet y González, 2001, 804-805).

En 1991, el gobierno mexicano propuso a sus homólogos centroamericanos negociar un Tratado de Libre Comercio (TLC). Sin embargo, no todos los países de la región estuvieron en posibilidades de hacerlo debido a las condiciones políticas internas. Solo Costa Rica y Nicaragua firmaron un tratado de libre comercio con México, la primera en 1995 y la segunda en 1998 (Castillo, Toussaint y Vázquez, 2011, 230-231). Los principales resultados de estos tratados fueron los siguientes: concentración de las exportaciones costarricenses a México en el rubro de componentes de computadora y aceite de palma en bruto; crecimiento de la inversión mexicana en Costa Rica en términos absolutos; concentración de la inversión mexicana en la industria costarricense de

12 Todos los convenios y tratados mencionados en este apartado pueden consultarse en la página de la Secretaría de Relaciones Exteriores de México (www.sre.gob.mx). 
alimentos, el comercio, los servicios y la construcción; incremento del intercambio comercial entre México y Costa Rica en 650\%; incremento de la inversión tica en México; aumento del volumen total de las exportaciones mexicanas a Nicaragua en 595\%; incremento del total de mercancías exportadas de Nicaragua a México (maní, ganado en pie, carne bovina, cuero y ron) en 585\% (Orduña, 1998, 263-266).

A principios de 1996, México inició las negociaciones para la firma del Tratado de Libre Comercio con los países del Triángulo del Norte (Guatemala, El Salvador y Honduras), las cuales culminaron en el año 2000. Los objetivos del tratado eran ampliar y normar sus relaciones comerciales; incrementar las oportunidades de mercado para la industria, el agro y el comercio; beneficiar a los consumidores con más y mejores productos; atraer inversión extranjera que ayudara a generar empleos; y contar con un mecanismo ágil de solución de controversias comerciales. A partir de entonces, los países del Triángulo del Norte se convirtieron en el principal mercado de México en América Latina. El monto total de las importaciones de México provenientes de estos países se incrementaron, al tiempo que las ventas de productos mexicanos a esta región registraron un monto superior a la suma de las exportaciones de productos mexicanos a Brasil, Argentina y Chile (Castillo, Toussaint y Vázquez, 2011, 231). Por ello, con una visión pragmática enfocada en lograr acuerdos de liberalización comercial, al finalizar el sexenio de Felipe Calderón México impulsó la firma de un Tratado de Libre Comercio Único con Centroamérica, con el fin de consolidar los acuerdos previos con Nicaragua, Costa Rica y los países del Triángulo del Norte (González y Velázquez, 2013, 603; Alcázar, 2013, 17).

No obstante, en términos relativos, el comercio entre México y Centroamérica ha seguido teniendo una muy escasa relevancia, incluso después de la firma de los Tratados de Libre Comercio con los países de la región. No solo contrasta con las enormes cifras del comercio de México con América del Norte, especialmente con Estados Unidos, sino que existen otras regiones del mundo que se encuentran por encima de los países centroamericanos en cuanto a las cifras de sus vínculos comerciales con México. Si bien la iniciativa de crear una zona de libre comercio con Centroamérica partió de México, es claro que sus intereses en la región no son tanto comerciales como geopolíticos. Más allá de las posibles relaciones económicas, lo prioritario para México han sido los problemas políticos en el istmo (Guerra Borges, 1996, 58; Villafuerte, 2001, 305). Por ello, su interés en el ámbito económico-comercial y de desarrollo tiene que ver, sobre todo, con la posibilidad de alcanzar otros objetivos más importantes vinculados con la construcción de una hegemonía regional, la seguridad de sus fronteras y la estabilidad interna (Macouzet y González, 2001, 806). 


\section{Conclusión}

Es evidente que, de los años ochenta a la fecha, se pasó de una política de claro interés en Centroamérica, cuyas acciones contribuyeron a la paz en la región, a nuevos esquemas de cooperación que fueron diluyendo el activismo mexicano. En términos generales, podemos afirmar que la política hacia la región centroamericana a fines de los años setenta y principios de los ochenta, aumentó el prestigio de México a nivel internacional y elevó las dimensiones de su influencia regional, derivando en una ampliación de su capacidad de negociación frente a Estados Unidos, lo que se tradujo en la institucionalización de un margen más amplio de autonomía política. Sin embargo, para mediados de 1982, el gobierno saliente de López Portillo no pudo continuar con esa política debido a la crisis, a la pérdida del apoyo de otros países latinoamericanos y a las crecientes presiones por parte del gobierno estadounidense. De este modo, el único intento para dotar a México de una verdadera política centroamericana, convirtiéndolo en un protagonista de primer nivel en la crisis regional, fue el que tuvo mayores efectos indirectos los cuales lo volvieron insostenible. Así, aunque el sexenio de Miguel de la Madrid implicó una cierta continuidad en cuanto a la política exterior de México hacia Centroamérica, el cambio fundamental fue que se transitó de sostener una posición de clara defensa hacia una de las partes en conflicto a ejercer el papel de intermediador $y$, en algunos casos, a retirar el apoyo otorgado hasta entonces.

A pesar de la firma de los acuerdos de paz de Guatemala y El Salvador, en cuyo proceso de negociación participó México de manera destacada, años más tarde se haría evidente que ello no había significado la superación o la solución de las causas de la crisis centroamericana. Los problemas regionales y nacionales se han agravado aún más y no se ha encontrado solución a algunos asuntos como concentración del poder, seguridad, tenencia de la tierra, grupos étnicos marginados, vivienda, alimentación, salud, trabajo o educación. Poco se ha logrado en el control de la violencia y la defensa de los derechos humanos y, tanto los problemas económicos como los sociales, se han convertido en elementos latentes que han empezado a expresarse en los conflictos más recientes en la región. De aquí la importancia de las Cumbres de Tuxtla, las cuales se abocaron a analizar y buscar soluciones conjuntas a los principales problemas de la región, a través de los mecanismos de cooperación. En Tuxtla I se reconoció la importancia de los países centroamericanos para la seguridad nacional de México; Tuxtla II fue un impulso al concepto de la asociación privilegiada entre México y Centroamérica; Tuxtla III significó la institucionalización de la cooperación regional y el fomento de la integración regional centroamericana; mientras que Tuxtla IV implicó la redefinición de Mesoamérica y la reformulación de nuevos proyectos de desarrollo.

Con todo, ante el fracaso rotundo del Plan Puebla Panamá y los escasos logros del Proyecto Mesoamérica, parece necesario revisar los objetivos y las 
acciones establecidas en este último, que deberían estar encaminados a la solución de los problemas actuales de Centroamérica -pobreza, desigualdad, inestabilidad política, violencia, desastres, narcotráfico, migración- los cuales demandan hoy mucho más de la cooperación mexicana hacia la región. Los retos actuales para México en materia de cooperación hacia Centroamérica se enmarcan en tres temas principales: migración, seguridad y libre comercio. Para ello, se debe tomar en cuenta que en la región han confluido los graves rezagos económicos y sociales de carácter estructural con una serie de factores en términos de seguridad pública, crisis económica y debilidad institucional, que hoy requieren una mayor voluntad política por parte de los gobiernos para alcanzar una solución. La primera gran pregunta es si el gobierno mexicano está dispuesto a colocar a Centroamérica como una de sus prioridades en materia de política exterior, y formular iniciativas económicas, políticas y sociales que contribuyan a garantizar la estabilidad política y el desarrollo económico y social de la región. La otra gran duda es si los actuales gobiernos centroamericanos están dispuestos a dejar atrás una historia de autoritarismo, violencia y privilegios, para poner en el centro las necesidades de las mayorías en cada uno de sus países. Desafortunadamente, las respuestas a estas preguntas no parecen ser muy alentadoras.

\section{Referencias}

Alba Vega, Carlos. Kruijt, Dirk. (2007). Viejos y nuevos actores violentos en América Latina: temas y problemas. Foro Internacional, (189), 485-516.

Alcázar, Marco Antonio. (2013). México y Centroamérica: en búsqueda de una política integral. En Villamar, Zirahuén. (Ed.). Análisis Político. México y América Central: una perspectiva estratégica e integral de seguridad. México: Friedrich Ebert.

Álvarez Fuentes, Jorge. (2001). La cooperación México-Centroamérica. Una perspectiva histórica contemporánea. En Benítez Manaut, Raúl y Fernández de Castro, Rafael. (Eds.). México-Centroamérica. Desafíos a inicios del siglo XXI. México: Instituto Tecnológico Autónomo de México.

Ángeles Cruz, Hugo. (2004). Las bandas maras salvatruchas en la región fronteriza del Soconusco, Chiapas. En Sánchez, J. E. y Jarquín, R. (Eds.). La frontera sur. Reflexiones sobre el Soconusco, Chiapas y sus problemas ambientales, poblacionales y productivos. México: El Colegio de la Frontera Sur.

Arriola, Mario. (1986). En torno a las negociaciones del Grupo Contadora, hoy. Cuadernos de Política Exterior Mexicana, (2), 277.

Benítez Manaut, Raúl. (2001). Procesos de paz en Centroamérica y México: génesis y desafíos pendientes a inicios del siglo XXI. En Benítez Manaut, Raúl 
y Fernández de Castro, Rafael. (Coords.). México-Centroamérica. Desafíos a inicios del siglo XXI. México: Instituto Tecnológico Autónomo de México.

Benítez Manaut, Raúl. (2007). Pros y contras de la Iniciativa Mérida. EnfoqueReforma, (715), 13-15.

Benítez Manaut, Raúl. Córdova Macías, Ricardo. (Eds.). (1989a). La paz en Centroamérica: expediente de documentos fundamentales, 1979-1989. México: Universidad Nacional Autónoma de México-Centro de Investigaciones Interdisciplinarias en Humanidades.

Benítez Manaut, Raúl. Córdova, Ricardo. (Eds.) (1989b). México-Centroamérica: percepciones mutuas y trayectoria de las relaciones (1979-1986). En México en Centroamérica, expediente de documentos fundamentales, (1979-1986), México: Universidad Nacional Autónoma de México-Centro de Investigaciones Interdisciplinarias en Humanidades.

Best, Edward. (1987). US Policy and Regional Security in Central America. New York: St. Martin's Press.

Castañeda, Jorge G. Pastor, Robert. (1989). Límites en la amistad: México y Estados Unidos. México: Joaquín Mortiz-Planeta.

Castillo, Manuel Ángel. (2000). Las políticas hacia la migración centroamericana en países de origen, de destino y de tránsito. Papeles de Población, (24), 133-157.

Castillo, Manuel Ángel. (2005). Actores y políticas en torno a la migración en la frontera sur de México. En Guillén, Diana. (Ed.). Chiapas: frontera en movimiento. México: Instituto de Investigaciones José María Luis Mora.

Castillo, Manuel Ángel. Herrera, C.A. (2006). Centroamericanos en México y en Estados Unidos: tendencias y políticas migratorias. México: El Colegio de México.

Castillo, Manuel Ángel. Toussaint, Mónica. (2010a). Migraciones centroamericanas en el estado de Chiapas y sus impactos socioculturales. En Migraciones: mirando al sur. Entrecruzamientos culturales en las migraciones centroamericanas. México: Instituto Nacional de Migración-Agencia Española de Cooperación Internacional para el Desarrollo.

Castillo, Manuel Ángel. Toussaint, Mónica. (2010b). Seguridad y migración en la frontera sur de México. En Alvarado, Arturo y Serrano, Mónica. (Eds.). La seguridad de México en el siglo XXI. México: El Colegio de México.

Castillo, Manuel Ángel. Toussaint, Mónica. Vázquez, Mario. (2011). Centroamérica. México: Acervo Histórico Diplomático-Secretaría de Relaciones Exteriores. 
Comisión Mexicana de Ayuda a Refugiados. (2000). México, tradición de asilo y refugio. México: Secretaría de Gobernación.

Comisión para el Esclarecimiento Histórico. (1999). Guatemala. Memoria del silencio. Informe de la Comisión para el Esclarecimiento Histórico. Guatemala: Oficina de Servicios para Proyectos de las Naciones Unidas.

Contadora. (1984). Acta de Contadora para la paz y la cooperación en Centroamérica. Revista Mexicana de Política Exterior, (4), 85-102.

Córdova Macías, Ricardo. (2001). El cumplimiento de los acuerdos de paz y los retos para la gobernabilidad democrática en El Salvador. En Benítez Manaut, Raúl y Fernández de Castro, Rafael. (Coords.). México-Centroamérica. Desafíos a inicios del siglo XXI. México: Instituto Tecnológico Autónomo de México.

Covarrubias, Ana. (2013). La política exterior de Calderón: objetivos y acciones. Foro Internacional, (213-214), 455-482.

Covarrubias, Ana. Muñoz, Laura. (2007). Manuel Tello: por sobre todas las cosas México. México: Secretaría de Relaciones Exteriores-Instituto Matías Romero.

Cuenca, Breny. (1984). Repercusiones de la declaración franco-mexicana sobre El Salvador. Cuadernos de Política Exterior Mexicana, (1), 91.

Cueva, Agustín. (1987). Las raíces del conflicto centroamericano. En Centroamérica: una historia sin retoque. México: El Día.

Declaración Conjunta. (1991). I Reunión de jefes de Estado y de gobierno de Centroamérica y México (Tuxtla I). Tuxtla Gutiérrez, Chiapas, 11 de enero. Recuperado noviembre 1, 2013 de http://www.sieca.int/Documentos

Declaración Conjunta. (1996). I/ Reunión de jefes de Estado y de gobierno de Centroamérica y México (Tuxtla II). San José de Costa Rica, 16 de febrero. Recuperado el $1^{\circ}$ de noviembre del 2013 de: http://www.sieca.int/Documentos

Declaración Conjunta. (1998). III Reunión de jefes de Estado y de gobierno de los países integrantes del mecanismo de diálogo y concertación de Tuxtla (Tuxtla III). San Salvador, El Salvador, 17 de julio. Recuperado el $1^{\circ}$ de noviembre del 2013 de: http://www.sieca.int/Documentos

Declaración Conjunta. (2000). IV Cumbre de los jefes de Estado y de gobierno de los países integrantes del mecanismo de diálogo y concertación de Tuxtla. Ciudad de Guatemala, Guatemala, 25 de agosto. Recuperado el $1^{\circ}$ de noviembre del 2013 de: http://www.sieca.int/Documentos 
Declaración Conjunta. (2001). Cumbre extraordinaria de los países integrantes del mecanismo de diálogo y concertación de Tuxtla. San Salvador, El Salvador, 15 de junio. Recuperado el $1^{\circ}$ de noviembre del 2013 de: http:// www.sieca.int/Documentos

Declaración Conjunta. (2004). VI Cumbre de jefes de Estado y de gobierno del mecanismo de diálogo y concertación de Tuxtla. Managua, Nicaragua, 25 de marzo. Recuperado el $1^{\circ}$ de noviembre del 2013 de: http://www.sieca. int/Documentos

Declaración Conjunta. (2007). Cumbre de mandatarios para el fortalecimiento del Plan Puebla Panamá. Ciudad de Campeche, Campeche, 10 de abril. Recuperado el $1^{\circ}$ de noviembre del 2013 de: de http://www.sieca.int/Documentos

Declaración Conjunta. (2008). X Cumbre de jefes de Estado y de gobierno del mecanismo de diálogo y concertación de Tuxtla. Villahermosa, Tabasco, 27 y 28 de junio. Recuperado el $1^{\circ}$ de noviembre del 2013 de: http://www. sieca.int/Documentos

Diskin, Martin. (1983). Trouble in our Backyard. Central America and the United States in the Eighties. New York: Pantheon Books.

Garcés Contreras, Guillermo. (1982). México. Cincuenta años de política internacional. México: Instituto Centroaméricano de Administración Pública.

González González, Guadalupe. Velázquez Flores, Rafael. (2013). La política exterior de México hacia América Latina en el sexenio de Felipe Calderón (2006-2012): entre la prudencia política y el pragmatismo económico. Foro Internacional, (213-214), 572- 618.

Gordon, Sara. (1993). México frente a Centroamérica. México: Universidad Nacional Autónoma de México-Instituto de Investigaciones Sociales.

Guerra-Borges, Alfredo. (1996). La integración centroamericana ante el reto de la globalización. Managua: Coordinadora REgional de Investigaciones Económicas y Sociales.

Herrera Lasso, Luis. (1990). México frente a Centroamérica: emergencia de un nuevo activismo. En Cristina Eguizábal. (Ed.). América Latina y la crisis centroamericana: en busca de una solución regional. San José: Consejo Superior Universitario Centroaméricano.

Lafeber, Walter. (1985). The Reagan Policy in Historical Perspective. En Kenneth M. Coleman y George C. Herring. The Central American Crisis. Sources of Conflict and the Failure of US Policy. Wilmington, Delaware: Scholarly Resources Inc. 
Lozoya, Jorge Alberto. (2001). La nueva política de cooperación internacional de México. Foro Internacional, (166), 931-938.

Macouzet Noriega, Ricardo. González Villanueva, Luis. (2001). La política y el comercio de México hacia América Latina: 1994-2000. Foro Internacional, (166), 784-818.

Ojeda Gómez, Mario. (2007). Retrospección de Contadora. Los esfuerzos de México para la paz en Centroamérica (1983-1985). México: El Colegio de México.

Orduña Trujillo, Joaquín. (1998). Tratados de Libre Comercio entre México y otros países. En Páez Montalbán, Rodrigo y Vázquez Olivera, Mario. (Eds.). Integración Latinoamericana. Organismos y Acuerdos (1948-2008). México: Universidad Nacional Autónoma de México-Centro de Investigaciones sobre América Latina y el Caribe.

Ortiz Taboada, Mónica. (1988). Relación de Contadora. México: Fondo de Cultura Económica-Secretaría de Relaciones Exteriores.

Páez Montalbán, Rodrigo (1998). La paz posible. Democracia y negociación en Centroamérica, 1979-1990. México: Instituto Panamericano de Geografía e Historia-Centro Coordinador y Difusor de Estudios Latinoamericanos.

Proyecto Mesoamérica. Recuperado el 1 de noviembre, 2013, de http://www. proyectomesoamerica.org/

Reyes Illescas, Miguel Ángel. (1997). Los complejos senderos de la paz. Un análisis comparado de las negociaciones de paz en El Salvador, Guatemala y México. Guatemala: Instituto Centroamericano de Estudios Políticos.

Rico, Carlos. (1984). México, Estados Unidos y el impasse de Contadora. Estudios Políticos, (4), 78.

Rico, Carlos. (1991). México y el mundo. Historia de sus relaciones exteriores. México: Senado de la República.

Rico, Carlos. (2008). La Iniciativa Mérida y el combate nacional al crimen organizado. Foreign Affairs en Español, (1), 3-13.

Rocha, Alberto. (2006). La geopolítica de México en Centro América: ¿una hegemonía regional? Sociologías, (16), 308-359.

Rodríguez Chávez, Ernesto. (2006). Frontera sur y política migratoria en México (circularidad, seguridad y derechos humanos), Foreign Affairs en Español, (4), 64-70.

Rojas Aravena, Francisco. (1990). Costa Rica: política exterior y crisis centroamericana. Heredia: Universidad Nacional. 
Rouquié, Alan. (1994). Guerra y paz en América Central. México: Fondo de Cultura Económica.

Ruiz Marrujo, Olivia. (2001). Los riesgos de cruzar. La migración centroamericana en la frontera México-Guatemala. Frontera Norte, (25), 7-33.

Samayoa, Salvador. (2007). El Salvador. La reforma pactada. San Salvador: UCA Editores.

Santamaría Troncoso, Rodolfo. (2008). Sistema de Integración Centroamericana (SICA). En Páez Montalbán, Rodrigo y Vázquez Olivera, Mario. (Eds.). Integración Latinoamericana. Organismos y Acuerdos (1948-2008). México: Universidad Nacional Autónoma de México-Centro de Investigaciones sobre América Latina y el Caribe.

Secretaría de Relaciones Exteriores. (1990). 20 años de política exterior a través de los informes presidenciales 1970-1990. México: Secretaría de Relaciones Exteriores.

Sepúlveda, Bernardo. (1984). Reflexiones sobre la política exterior de México. Foro Internacional, (96), 407-414.

Serna Moreno, Eva María. (1998). El Plan Puebla-Panamá (PPP), ahora Proyecto Mesoamérica. En Páez Montalbán, Rodrigo y Vázquez Olivera, Mario. (Eds.), Integración Latinoamericana. Organismos y Acuerdos (19482008). México: Universidad Nacional Autónoma de México-Centro de Investigaciones sobre América Latina y el Caribe.

Sosnowska, Joanna. (2006). Política exterior de México: dimensión regional e internacional. México: Universidad Nacional Autónoma de México-Centro Coordinador y Difusor de Estudios Latinoamericanos.

Torres Rivas, Edelberto. (1984). ¿Quién destapó la Caja de Pandora? (Reflexiones sobre la crisis y los sujetos del conflicto en Centroamérica). En Camacho, Daniel y Rojas B., Manuel. La crisis centroamericana. San José: EDUCA-Facultad Latinoamericana de Ciencias Sociales.

Toussaint, Mónica. Rodríguez de Ita, Guadalupe. Vázquez, Mario. (2001). Vecindad y diplomacia. Centroamérica en la política exterior mexicana, 18211988. México: Acervo Histórico Diplomático-Secretaría de Relaciones Exteriores.

Valero, Ricardo. (1985). Contadora: la búsqueda de la pacificación en Centroamérica. En Política Exterior de México. 175 años de historia. México: Secretaría de Relaciones Exteriores. 
Velázquez Flores, Rafael. Domínguez, Roberto. (2013). Balance de la política exterior de México en el sexenio de Felipe Calderón bajo los tres niveles de análisis: límites y alcances. Foro Internacional, (213-214), 483-516.

Villafuerte Solís, Daniel. (2001). Integraciones comerciales en la frontera sur. Chiapas frente al Tratado de Libre Comercio México-Centroamérica. México: Universidad Nacional Autónoma de México-Programa de Investigaciones Multidisciplinarias sobre Mesoamérica y el Sureste. 